\title{
A EDUCAÇÃO PERANTE A NOVA ORDEM MUNDIAL*
}

Maria D Rosila VAsConCELlos ${ }^{* *}$

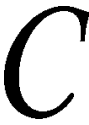

hristian Laval despontou na cena francesa com seu livro sobre L'ambition sociologique (A ambicão sociológica, 2002), onde aborda 0 vínculo muito estreito entre sociologia e economia política. Além de professor de ciências econômicas e sociais num colégio parisiense, ele também é muito atuante num sindicato de docentes, membro da importante Federação dos Sindicatos Unificados (FSU), a qual lidera o movimento que tanto agitou, desde maio último, os meios docentes. Entretanto, foi seu livro L'école n'est pas une entreprise (A escola não é uma empresa, 2003), com seu subtítulo muito eloqüente: L e néolibéralisme à l'assaut de l'enseignement public (A s investidas do neoliberalismo contra 0 ensino público), que 0 revelou entre os militantes dos movimentos alter-mundialistas. E preciso guardar em mente que a França é um dos países desenvolvidos em que a questão da introdução de políticas neoliberais é raramente analisada como "sistema de idéias" coordenado e coerente, oriundo de teorias econômicas e sociopolíticas precisas, espalhadas e preconizadas principalmente por instituições internacionais como o FMI, o Banco Mundial, a OCDE, as comissões da União Européia e a atualmente mais em vista oMc.

D esde os anos 90, alguns intelectuais que se situam à "esquerda da esquerda" têm se dedicado a denunciar as novas orientações

\footnotetext{
* Resenha do livro de Christian Laval, L'éole n'est pas une entreprise. Le néo-libéralisme à l'assaut de l'enseignement public (Paris: La D écouverte, 2003). Tradução da resenha por Alain François.

* Professora de Sociologia da Educação na Universidade Lille 3, França. E -mail: vasconcellos@ wanadoo.fr
} 
oriundas das políticas neoliberais. O ra, embora a educação esteja profundamente afetada, isso não motivou pesquisas específicas no meio universitário. Nesse sentido, o livro de Christian Laval faz época. Nele, o autor denuncia as primícias dessas teorias econômicas e seus efeitos sobre as políticas educativas fomentadas, desde os anos 80, na maioria dos países. O bviamente, como são mais "dependentes" das injunções do FMI ou do Banco Mundial, os países da América latina, assim como outros do hemisfério Sul, se empenharam mais para adotar as medidas preconizadas. Mesmo assim, segundo o autor, na Europa, e mais particularmente na França, essas orientações foram implementadas "disfarçadamente". Assim, a partir de alguns traços significativos que caracterizam as mudanças no sistema de ensino, este livro busca desvendar a "mão invisível" do neoliberalismo. D esde os anos 80, o medo da impopularidade conduziu os principais responsáveis dos governos sucessivos a iniciar reformas de modernização ou a introduzir inovações pedagógicas ou modalidades de organização dos poderes dentro da escola, notadamente por meio de políticas de descentralização ou pela promoção dos estabelecimentos escolares ou de nível superior. Segundo Laval, os argumentos subjacentes a essas mudanças parecem se originar diretamente nas diretivas preconizadas por esses organismos internacionais que vêem nos sistemas de ensino novos produtos, situados no mercado da educação.

Ainda segundo este autor, nas orientações neoliberais, a palavra "escola" "designa um certo modelo escolar que considera a educação como um bem essencialmente privado e cujo valor é antes de tudo econômico". Não é mais a sociedade que garante a todos os seus membros um direito à cultura, mas os indivíduos que devem capitalizar recursos privados aos quais a sociedade garantirá um rendimento futuro. Essa privatização afeta tanto os saberes e as instituições, cuja função seria justamente a de transmitir valores e conhecimentos, quanto o próprio laço social. 0 único objetivo da idéia de autonomia patenteada nessas orientações é 0 de garantir o serviço dos interesses particulares. $\mathrm{O}$ autor passa então a destrinchar a noção de capital humano, desde sua origem nos Estados Unidos. A partir de uma análise detalhada de seu sucesso entre os economistas anglo-saxões e de sua difusão pelas instâncias internacionais, especialmente em matéria de educação, ele propõe avaliar a escola por meio dessa noção, considerada como um instrumento de bem-estar econômico cuja ambição é a de garantir tanto um capital humano para as empresas como conhecimentos, os quais são uma ferramenta de cunho individual. Ela 
permitiu que a educação pudesse incorporar a idéia de capitalismo liberal e abrisse um amplo lugar para o mercado escolar. Considerar os conhecimentos como recursos privados que favorecem rendas e posições sociais mais vantajosas leva a ver a relação educativa como regida por relações de tipo comercial, o que se adapta perfeitamente ao modelo de mercado.

A seguir, o autor busca demonstrar que, desde os anos 60, a massificação do ensino médio ou universitário ocorreu sem uma real vontade política, uma vez que, "mal pensada, mal preparada, pouco financiada", "ela acarretou problemas" que acabaram tomando proporções dramáticas em razão da penúria de docentes, da superlotação das salas de aula e da falta de recursos. Laval ressalta então que, já há uns trinta anos, esses problemas induzem regularmente movimentos de protesto entre os funcionários da educação e, em razão de suas dificuldades cotidianas, o "desgaste moral" dos docentes, evocado em várias oportunidades por ministros sucessivos. O ra, as soluções de tipo liberal tendem a favorecer todas as contradições e disfunções da escola, uma vez que os problemas não seriam mais "sociais", mas de uma "civilização" onde o acesso à cultura - letrada, escrita, científica ou técnica - é uma utopia. Diante da contenção das despesas públicas e do desejo de baixar as contribuições compulsórias, o direito à educação passa a inscrever-se na esfera privada e apenas a "demanda social" adimplente seria recompensada. Isso sem dúvida aumenta e legitima as desigualdades sociais perante a educação. 0 autor analisa então a "linguagem" usada pelos tomadores de decisão no que diz respeito à educação. Ele ataca a idéia de um "aprendizado ao longo da vida toda" e especificamente o uso do termo "formação", o qual invadiu as políticas educativas francesas e criou uma distinção entre formação inicial e formação continuada profissional. A finalidade profissional parece reger as etapas de "formação", "cada uma delas preparando para a próxima". As aprendizagens escolares seriam orientadas para a inserção profissional e a aquisição de conhecimentos é pensada somente como base de competências necessárias ao trabalhador polivalente e flexível. D aí a valorização das aprendizagens sociais - comunicação, apresentação de si, capacidade de resolver problemas em situação de incerteza - que acompanham os conhecimentos cada vez mais especializados. Lançada em 1970 pela UNESCO e retomada em 1996 pela OCDE, a idéia de uma aprendizagem ao longo da vida toda parece digna de elogios numa perspectiva humanista. Ela representaria um progresso em termos de percurso de aprendizagem, de recuperação ou de aperfeiçoa- 
mentos continuados. Ora, segundo os discursos e as orientações políticas inspiradas por essa idéia, a estrutura da educação deve ser recomposta por novas "formas de aprendizagem pela vida toda". A "oferta de formação" deve não apenas se diversificar como se desenvolver em "parceria" com órgãos financiadores, especificamente 0 empresariado.

Ao lado da educação formal (a escola), existiria uma educação informal (experiência profissional ou social) que visa a reforçar as iniciações práticas no trabalho. 0 sistema de formação integra assim um processo contínuo de adaptação às situações complexas e sujeitas a mudanças. A crítica dos saberes "acadêmicos" ocorre pela introdução de noções diversas como "organizações aprendedoras", redes de aprendizagem, itinerários flexíveis, pontes, parceria e muitas outras que compõem uma "sociedade cognitiva".

Entre essas mudanças institucionais, uma das noções mais utilizadas é a de "competência" que tende a se substituir à de conhecimentos ou, no universo profissional, à de qualificação. Este uso, em contextos de ação social diversos, da noção de competência liga-se a objetivos amplos como "aprender a ser, a fazer, a viver junto, a conhecer" etc. A opacidade deste termo, que se deve tanto a seu sentido variado segundo as disciplinas (direito, lingüística, psicologia etc.) quanto aos atores que 0 usam, acarreta novas dificuldades no processo de aprendizagem, notadamente em termos de reconhecimento ou de valorização das capacidades adquiridas. No sistema francês de categorização dos assalariados, o diploma constituía a base das remunerações, segundo grades de qualificações estabelecidas por convenções coletivas entre o Estado, os empregadores e os assalariados. A introdução da noção de competência implica a valorização de conhecimentos adquiridos na prática e reconhecidos por meio de um conjunto de ferramentas de avaliação. O ra, por um lado, as capacidades avaliadas têm sua origem num tipo de organização produtiva e, por outro, o assalariado fica assim submetido ao arbitrário de avaliações individuais, de estratégias empresariais. Ao valorizar a dimensão "pessoal" na administração moderna, a gestão das competências se torna um novo meio de individualização e de "responsabilização" de cada um diante de suas dificuldades, jogando em cima do assalariado o peso de suas incapacidades de integrar-se num grupo e a abraçar os objetivos da empresa, e sua falta de motivação etc. Deste modo, a formação "inicial" (a escola) é criticada na sua capacidade de dotar os alunos das qualidades reconhecidas no mercado. Os discursos da OCDE analisados pelo autor esclarecem esse objetivo da passa- 
gem de uma "lógica dos conhecimentos" a uma "lógica de competências": desenvolver capacidades de adaptação, de comunicação, de trabalho em equipe, de espírito de iniciativa etc.

Em suma, a escola desejada por essas políticas neoliberais tem duas características principais: a submissão aos imperativos econômicos e a dependência das demandas dos diferentes componentes da sociedade, entre os quais estão os pais. Ela apenas concebe o saber na sua dimensão de ferramenta para agir, de instrumento para ter êxito social, de capital individual para aumentar as rendas futuras. 0 "capital humano" é a pedra angular da reorientação dos dispositivos educativos e até mesmo o próprio espírito da educação. De fato, a noção de "serviço público" é desviada, segundo o autor, que vê nesta escola uma "agência de serviços" encarregada de satisfazer "eficientemente" seus consumidores ao fazer valer seus interesses particulares. D aí a ênfase dada aos métodos empresariais, com sua cultura "patronal", sua linguagem e suas práticas. Os estabelecimentos escolares são agora dirigidos por chefes que se tornaram "patrões"; as especificidades do ofício de docente se apagam em benefício de definições assimiladas às dos técnicos da pedagogia ou dos executivos. A escola tende a se privatizar não necessariamente no plano jurídico ou financeiro, mas pela transformação interna em mercado em que a concorrência entre indivíduos ou entre estabelecimentos é de regra.

A outra figura emblemática dessa política é a descentralização absolutamente preconizada como reposta às aspirações a muito mais democracia ou a uma maior proximidade, segundo Laval. Ela é pensada em termos de adaptação estreita entre formações propostas e possibilidades locais de emprego. Daí o movimento importante rumo à profissionalização dos estudos universitários que submete os objetivos pedagógicos ou os conteúdos às "fontes de financiamentos" locais. Ou ainda às "áreas de educação prioritárias" para 0 ensino escolar, nas quais os créditos pedagógicos por aluno podem variar de 1 a 10, segundo as municipalidades.

O autor ainda ressalta as pressões do conselho europeu, que propõe um balanço anual dos sistemas de educação ou de formação na Europa. A idéia é elaborar 16 indicadores de qualidade que servirão para avaliar os sistemas nacionais para que possam ser comparados. A identidade dos objetivos e as relações de avaliação permitirão que cada um examine 0 caminho que resta a percorrer e possa tomar as medidas adequadas. Por seu lado, a o Mc propõe, no campo educativo, a liberação do comércio dos serviços educativos (escolas 
privadas, materiais pedagógicos etc.) para que os capitais investidos possam frutificar.

Contudo, essas políticas encontram resistências na opinião pública, pois surgem como ameaças contra 0 estatuto e o futuro de cada um. $\mathrm{O}$ autor elenca a seguir os movimentos sociais provocados pelas medidas preconizadas. Naturalmente, as manifestações que ocorreram, desde 1995 na França, demonstram o descontentamento de vários grupos sociais frente às políticas sociais ou educativas propostas. Mesmo assim, certas mudanças introduzidas no sistema educativo foram muito bem recebidas, em particular pelas famílias que aderiram às mudanças instituídas. As carreiras profissionais nas universidades atraem muito mais candidatos do que as ditas tradicionais.

Por isto, o trabalho de Laval, apesar de seu caráter de "denúncia" e de sua tentativa de "desmontagem" dos mecanismos subjacentes às políticas atuais, é um dos pioneiros nesse campo e convida pesquisadores experimentados a melhor analisar as implicações dessas políticas: como foram introduzidas, como a atuação política se desenvolveu, quais oposições ou adesões provocaram e, sobretudo, quais os efeitos que se fazem sentir nos vários segmentos do sistema de ensino. 